f. med. Genet. (1967). 4, 169.

\title{
A New Translocation Between Chromosomes in the 6-12 and 21-22 Groups
}

\author{
PATRICIA M. LORD, MICHAEL D. CASEY, and BERNARD M. LAURANCE
}

From the Department of Human Biology and Anatomy, University of Sheffield; the United Sheffield Hospitals Centre for Human Genetics; and Derbyshire Children's Hospital

Two families have been reported who show a translocation between chromosomes in the 6-12 group and the 21-22 group (Gray, Dartnall, Creery, and Croudace, 1966a; Gray, Dartnall, and Macnamara, 1966b). In one family only the mother of the propositus is mentioned as having the translocation in a balanced form, while in the other family the translocation is present, in a balanced form, in three generations. In each of these families the translocation, in an unbalanced form, is described in one infant, both of whom died at 4 months of age. The interpretation of the karyotypes is that one infant was trisomic for the long arms of a chromosome in the 6-12 group and that the other was trisomic for the short arms of a similar, or the same, chromosome.

In this paper a family is described which has a translocation between chromosomes in the 6-12 and 21-22 groups. This appears in a balanced form in two generations and in an unbalanced form in the third (Fig. 1) in which two sibs, IV. 1 and IV. 2, are apparently trisomic for part of a chromosome in the 6-12 group.

\section{Case Report}

IV. 1 and IV. 2 are the first and second born girl and boy, respectively, of healthy, mentally normal, unrelated parents (for dates of birth, see Table I). Both children were late in reaching their milestones and are mentally retarded (Table II). They have similar facies (Fig. 2a and 3a), widely patent fontanelles that closed after the age of 3, low-set prominent ears, transverse palmar creases, and short incurved fifth digits (Fig. 2b). They also had koilonychia (Fig. 3b), very flat feet, and a lumbar lordotic stance with flexion of the hips and knees that resulted in an unusual gait (Fig. 2c, 3c, 3d).

Linkage Studies and Blood Groups. Studies were carried out on the inheritance patterns of red cell

Received February 8, 1967. acid phosphatase, G6PD, and phosphoglucomutase, and the serum haptoglobulins, transferrins, and cholinesterase. Blood grouping was also carried out. No inconsistencies were found; the results are shown in Table III.

Dermatoglyphs. A study was made of the dermatoglyphs of most members of the family. The dermatoglyphic patterns of the unbalanced translocations IV. 1 and IV. 2 are closely similar (Fig. 4a and b), but not obviously abnormal in the two cases.

Fingers and Toes. The fingers of both patients show loop patterns only, a reduction of intensity as compared with most of their relatives. However, their father and maternal grandmother also have similar

TABLE I

DATES OF BIRTH OF MEMBERS OF THE FAMILY

\begin{tabular}{l|c}
\hline \multicolumn{1}{c|}{ Position in Pedigree } & Year of Birth \\
\hline I. 1 & 1881 ? \\
I. 2 & 1876 ? \\
\hline II. 1 & 1899 \\
II. 3 & 1901 \\
II. 4 & ? \\
II. 6 & 1905 \\
II. 7 & 1908 \\
II. 9 & 1910 \\
II. 10 & $?$ \\
II. 12 & 1913 \\
II. 13 & 1915 \\
II. 14 & 1918 \\
II. 15* maternal grandmother & 1920 \\
II. 16 maternal grandfather & 1915 \\
II. 17 & 1922 \\
II. 18 & 1924 \\
\hline III. 2 & 1926 \\
III. 3 & 1927 \\
III. 6 father & 1933 \\
III. 7* mother & 1939 \\
III. 8* & 1943 \\
III. 10 & 1949 \\
IV. 1† & 1952 \\
IV. 2f & 1960 \\
\hline
\end{tabular}

* Translocation carrier.

t Unbalanced translocation. 
TABLE II

PSYCHOLOGICAL TESTS

\begin{tabular}{|c|c|c|c|c|c|c|}
\hline \multirow{2}{*}{ Patient } & \multirow{2}{*}{ Date } & \multicolumn{4}{|c|}{ Merrill-Palmer Scale } & \multirow{2}{*}{$\begin{array}{c}\begin{array}{c}\text { Vineland Social } \\
\text { Maturity Scale }\end{array} \\
\text { Social } \\
\text { Age }\end{array}$} \\
\hline & & $\begin{array}{c}\text { Chronological } \\
\text { Age }\end{array}$ & $\begin{array}{l}\text { Mental } \\
\text { Age }\end{array}$ & Difference & $\begin{array}{c}\text { Intelligence } \\
\text { Rating }\end{array}$ & \\
\hline IV.1 & $\begin{array}{l}15.12 .64 \\
26.10 .65\end{array}$ & $\begin{array}{ll}4 & 0 / 12 \\
4 & 11 / 12\end{array}$ & $\begin{array}{ll}2 & 3 / 12 \\
3 & 0 / 12\end{array}$ & $\begin{array}{ll}-1 & 9 / 12 \\
-1 & 11 / 12\end{array}$ & $\begin{array}{l}\text { Very inf. (SD-2.5) } \\
\text { Very inf. (SD-2.5) }\end{array}$ & $39 / 12$ \\
\hline IV.2 & 26.10 .65 & $30 / 12$ & $110 / 12$ & $-12 / 12$ & Very inf. (SD-2.5) & $26 / 12$ \\
\hline
\end{tabular}

finger patterns. IV. 1 has radial loops on both her indices like her father. The maternal grandmother, their mother, and their uncle (III. 8) have radial loops on the right indices only. IV. 2 has a radial loop on his left hallux, which is an uncommon feature, but IV. 1 does not show this and it does not occur in any other relative.

Palms and Soles. The only marked peculiarities in common between IV. 1 and IV. 2 are zygodactyly of fingers III and IV on both hands with absence of triradius $c$.

An unusual open field pattern is present on the hallucal areas of all the soles, otherwise the patterns are of normal types. The unusual hallucal area pattern cannot be caused by abnormal chromosomes because it occurs on the soles of a chromosomally normal aunt (III. 10) and the normal maternal grandfather, and not in any of the relatives with the balanced translocation.

The possible pathological significance of the zygodactylous features on the hands is also rendered doubtful because the normal aunt (III. 10) also lacks triradius $c$ on her left hand.

Taking all the information provided, it appears that this particular kind of aneuploidy has no appreciable specific effect on the dermatoglyphic patterns.
Cytology. The karyotypes of IV. 1 and IV. 2 are shown in Fig. 5a and b. There are consistently 46 chromosomes; a chromosome is missing from the 21-22 group, and there is an extra chromosome in group 16. The Y chromosome in IV. 2 is apparently normal.

The karyotype of their 'mother (III. 7) is shown in Fig. 5c. There is again a chromosome missing from the 21-22 group and an extra No. 16, but there is also an extra chromosome in the 13-15 group and one missing from the 6-12 group. An identical autosomal karyotype was found in her brother (III. 8), her sister (III. 9), and her mother (II. 15), in whom 100 cells were counted in case she was a low percentage mosaic, but no discrepancies were found. Two attempts to culture skin biopsies for this purpose were unsuccessful, the mitotic index being very low and the figures very poor. Consent for further samples was refused.

Relatives II. 6, II. 9, II. 12, II. 13, II. 14, II. 17, II.18, and III. 2, III. 3, and III. 10, who were all phenotypically normal, were also chromosomally normal. Because of this, their offspring are not included in the pedigree (Fig. 1).

II. 3 and III. 1 were untraceable and consent was refused by II. 7 and for her offspring III. 4 and III. 5 .

III. 6, the phenotypically normal father of IV. 1 and IV.2, is also chromosomally normal except for a con-

TABLEZ⿱乛ु

BLOOD GROUPS; SERUM HAPTOGLOBULINS, TRANSFERRINS, CHOLINESTERASE; RED CELL ACID PHOSPHATASE,

\begin{tabular}{|c|c|c|c|c|c|c|c|c|c|c|}
\hline \multirow{2}{*}{$\begin{array}{l}\text { Position in } \\
\text { Pedigree }\end{array}$} & \multicolumn{10}{|c|}{ Blood Groups } \\
\hline & $\overline{\mathrm{ABO}}$ & Rhesus & MNS & $P$ & $\begin{array}{l}\text { Lutheran } \\
\mathbf{a} \text { b }\end{array}$ & $\mathrm{K}_{\mathrm{kell}}^{\mathrm{k}}$ & Donna & $\begin{array}{l}\text { Lewis } \\
\mathrm{a} \quad \mathrm{b}\end{array}$ & $\begin{array}{l}\text { Duffy } \\
a \quad b\end{array}$ & $\underset{a}{\text { Kidd }}$ \\
\hline $\begin{array}{l}\text { II. } 6 \\
\text { II. } 9 \\
\text { II. } 12 \\
\text { II. } 13 \\
\text { II. } 14 \\
\text { II. } 15 \\
\text { II. } 16 \\
\text { II. } 18 \\
\text { III. } 2 \\
\text { III. } 3 \\
\text { IIII. } 6 \\
\text { III. } 7 \\
\text { III. } 8 \\
\text { III. } 9 \\
\text { III. } 10 \\
\text { IV. } 1 \\
\text { IV. } 2\end{array}$ & $\begin{array}{c}\mathrm{O} \\
\mathrm{A}_{2} \\
\mathrm{O} \\
\mathrm{A}_{1} \\
\mathrm{O} \\
\mathrm{A}_{1} \mathrm{O} \\
\mathrm{A}_{1} \mathrm{O} \\
\mathrm{O} \\
\mathrm{O} \\
\mathrm{O} \\
\mathrm{A}_{1} \mathrm{~B} \\
\mathrm{O} \\
\mathrm{O} \\
\mathrm{O} \\
\mathrm{A}_{1} \\
\mathrm{BO} \\
\mathrm{A}_{1} \mathrm{O}\end{array}$ & 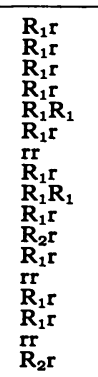 & 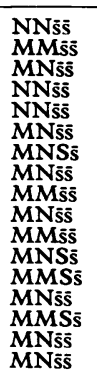 & $\begin{array}{l}\overline{ } \\
\pm \\
- \\
+ \\
+ \\
+ \\
+ \\
\overline{+} \\
+ \\
+ \\
+ \\
+ \\
+ \\
+\end{array}$ & $\begin{array}{l}a- \\
a- \\
a- \\
a- \\
a- \\
a- \\
a- \\
a-b+ \\
a-b+ \\
a-- \\
a- \\
a- \\
a+ \\
a- \\
a-\end{array}$ & $\begin{array}{l}\mathrm{K}= \\
\mathrm{K}= \\
\mathrm{K}= \\
\mathrm{K}= \\
\mathrm{K}= \\
\mathrm{K}= \\
\mathrm{K}= \\
\mathrm{K}= \\
\mathrm{K}=\mathbf{k}+ \\
\mathrm{K}=\mathbf{k}+ \\
\mathrm{K}+\mathbf{k}+ \\
\mathrm{K}= \\
\mathrm{K}= \\
\mathrm{K}= \\
\mathrm{K}= \\
\mathrm{K}+\mathbf{k}+ \\
\mathrm{K}-\end{array}$ & $\begin{array}{l}a- \\
a+ \\
a+ \\
a- \\
a+\end{array}$ & $\begin{array}{l}a-b+ \\
a-b+ \\
a-b+ \\
a-b+ \\
a-b+ \\
a-b+ \\
a- \\
a-b+ \\
a-b \\
a- \\
a-b+ \\
a-b+ \\
a-b+ \\
a-b+ \\
a-b+ \\
a-b+ \\
a-b+\end{array}$ & $\begin{array}{l}a- \\
a+ \\
a+ \\
a+ \\
a- \\
a- \\
a+ \\
a- \\
a-b+ \\
a-b+ \\
a+ \\
a+ \\
a+ \\
a+ \\
a+ \\
a+ \\
a+\end{array}$ & $\begin{array}{l}a+ \\
a+ \\
a+ \\
a+ \\
a+ \\
a+b+ \\
a+ \\
\\
a+b+ \\
a+b+ \\
a-b+ \\
a-b+ \\
a+b+ \\
a+b+\end{array}$ \\
\hline
\end{tabular}


I

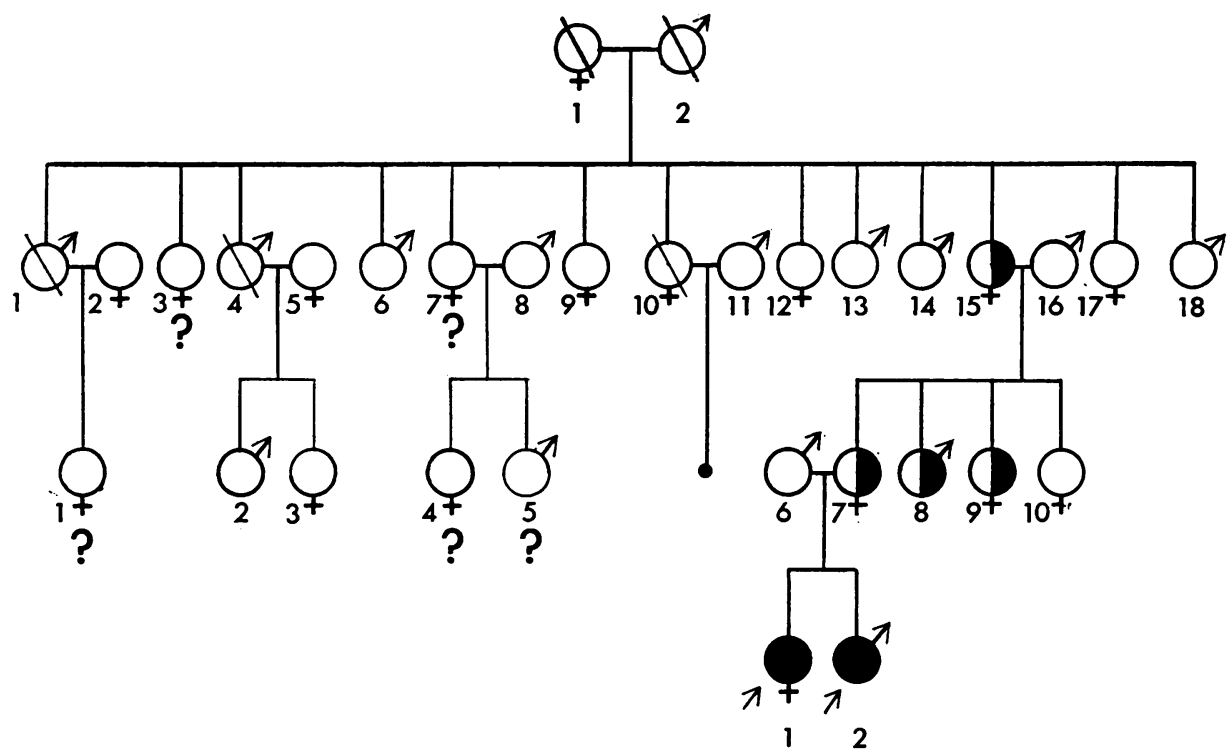

II
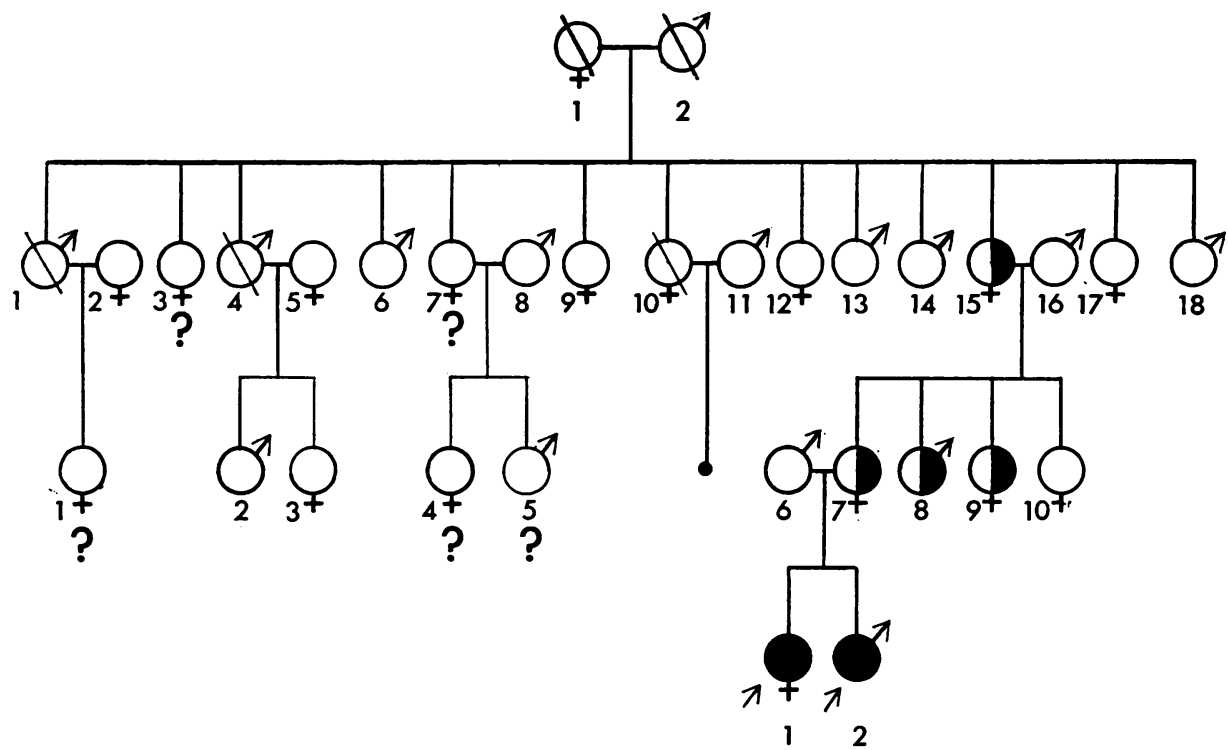

III

$\mathbb{Z}$

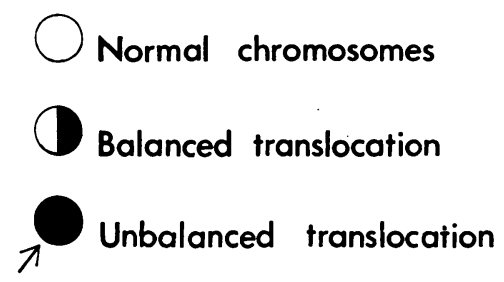

? Not examined-phenotype normal

Dead

- Miscarriage

Fig. 1. Pedigree of the family.

sistent slight difference in length between the two chromosomes in group No. 16. This difference was found in IV. 2 where one chromosome in group No. 16 was consistently longer than the other two. However, in IV. 1 and all the other carriers the chromosomes in group No. 16 were indistinguishable from each other. Because of this, the variation was considered to be familial and not related to the translocation.

As IV. 1 and IV. 2 both carry the same unbalanced translocation and have similar physical abnormalities

II

ILUCOSE-6-PHOSPHATE DEHYDROGENASE, PHOSPHOGLUCOMUTASE

\begin{tabular}{|c|c|c|c|c|c|c|c|c|c|}
\hline \multirow[b]{2}{*}{ Wright } & \multirow[b]{2}{*}{ Willis } & \multicolumn{2}{|c|}{ Serum } & \multicolumn{2}{|c|}{$\underset{\text { Cholinesterase }}{\text { Serum }}$} & \multicolumn{3}{|c|}{ Red Cell Enzymes } & \multirow[b]{2}{*}{$\begin{array}{c}\text { Position in } \\
\text { Pedigree }\end{array}$} \\
\hline & & Haptoglobulin & Transferrin & $\mathrm{C}_{5}$ & $U, I$, or $A$ & Acid phosphatase & G6PD & PGM & \\
\hline
\end{tabular}




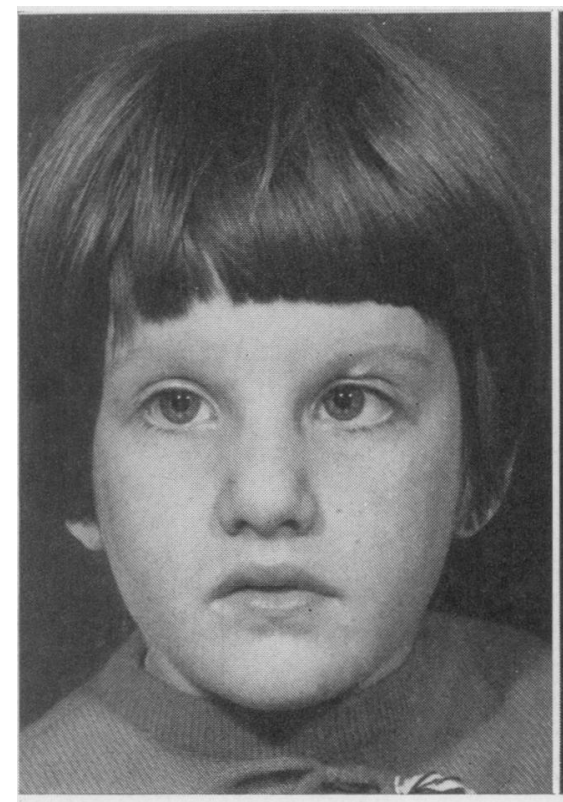

a

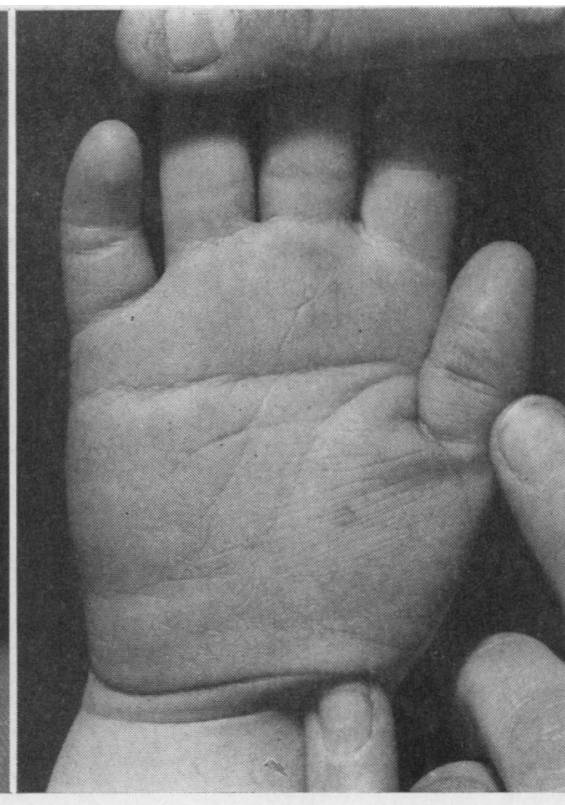

b

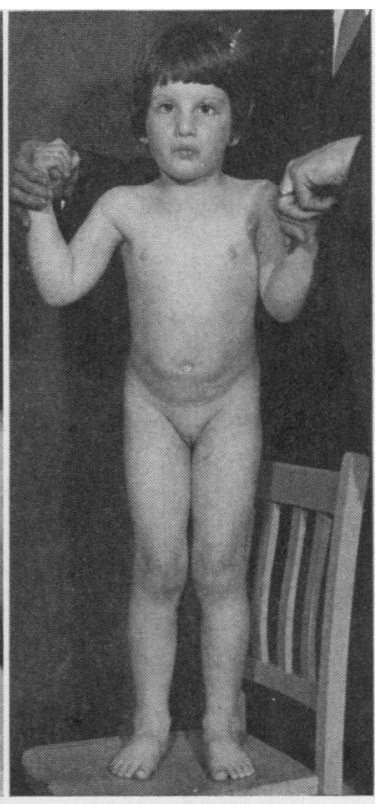

c

FIG. 2. Appearances in IV.1. (a) Note prominent base of nose and nodules over left eyelid. (b) Palmar crease, incurved fifth digit, juxtaposition of phalangeal creases, and short thumbs. (c) Stance: note flexion of hips and knees.

and mental subnormality we assume these to be due to the translocation.

It seems probable that the reciprocal translocation occurred in the gametes of either I. 1 or I. 2, as II. 15, the maternal grandmother, is the only person from the eight tested in her generation and III. 2 and III. 3, to carry the reciprocal translocation, and she shows no evidence of mosaicism in cultures from peripheral blood.

\section{Discussion}

The simplest explanation of the abnormal chromosomes is that the reciprocal translocation was between chromosomes from the 6-12 and 21-22 groups. The breaks might have occurred in either the short arms of both chromosomes or in the long arms of both chromosomes, in either case the break would be near to the centromere. An apparent extra member of the 13-15 group would be produced, consisting mainly of the long arms of the chromosome from the 6-12 group, and an apparent extra No. 16 consisting of most of the short arms of the chromosome from the 6-12 group and most of the chromosome from the 21-22 group. In the first case IV. 1 and IV. 2 with the unbalanced karyotypes would be trisomic for most of the short arms of the chromosome from the 6-12 group, in the second they would be trisomic for the short arms of the 6-12 chromosome together with its centromere.

A less likely explanation is that the breaks might have occurred further down the long arms of the chromosome in the 6-12 group and almost at the end of the long arms of the chromosome in the 21-22 group, a reciprocal translocation then taking place. In this case the apparent No. 13-15 chromosome would contain part or most of the chromosome from the 21-22 group and part of the long arms of the chromosome from the 6-12 group. The apparent No. 16 would consist almost entirely of material from the chromosome in the 6-12 group. This explanation is considered to be less likely because of the imbalance of chromosome material which would occur in IV. 1 and IV. 2 who would be trisomic for a large part of a chromosome from the 6-12 group and monosomic for a large part of a member of the 21-22 group.

It appears that the chromosome from the 6-12 group which is involved here is not the same one as either of those previously described in the two papers dealing with similar translocations; for the two affected children here described do not have the severe deformities described by the previous authors. 


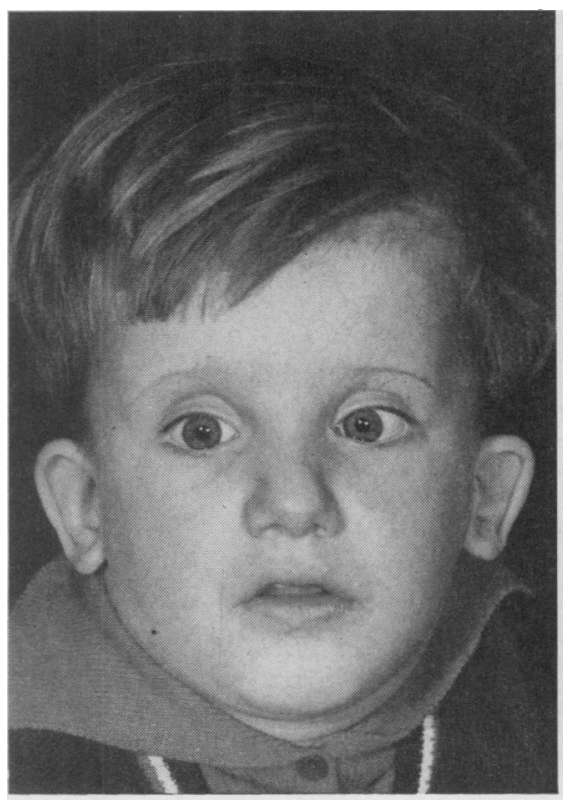

a

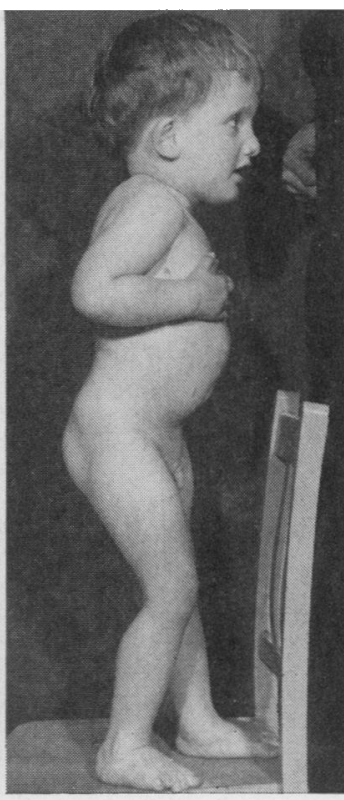

c

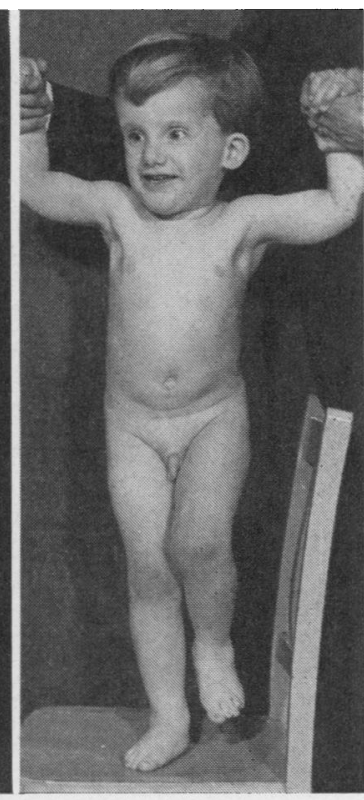

d

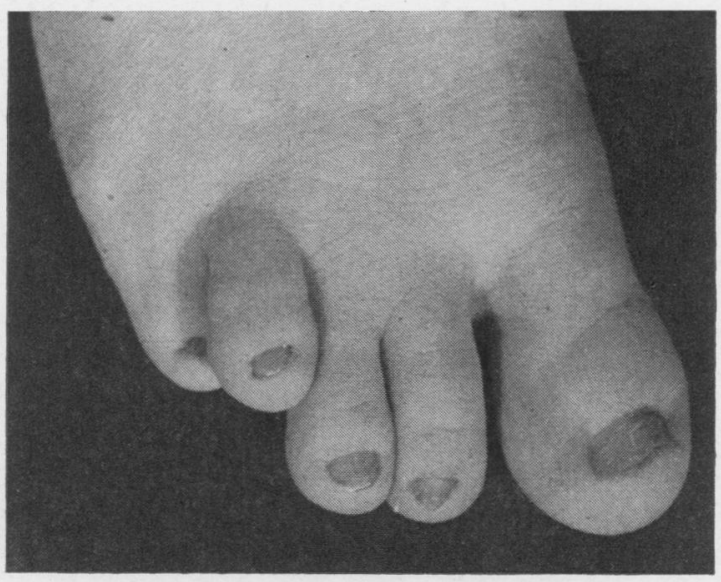

FIG. 3. Appearances in IV.2. (a) Facial appearance.

(b) Posture of toes and koilonychia.

(c) and (d) Stance.

\section{Summary}

A family is reported which shows a balanced translocation between chromosomes from the 6-12 group and the 21-22 group. This appears in a balanced form in four individuals from two generations and in an unbalanced form in two sibs in a third generation. The affected sibs are presumed to be trisomic for the short arms of a chromosome in the 6-12 group. The translocation here described is assumed to be different from the only two similar ones previously described, because in those cases the affected infants were grossly abnormal and died at 4 months of age.

Linkage studies, blood grouping, and dermatoglyphic studies were also carried out, but did not show anything of significance.

Acknowledgements are due to Mr. P. R. Stevens for psychological testing; Mr. B. Wilks for clinical photographs (Dept. of Medical Photography, Derbyshire 

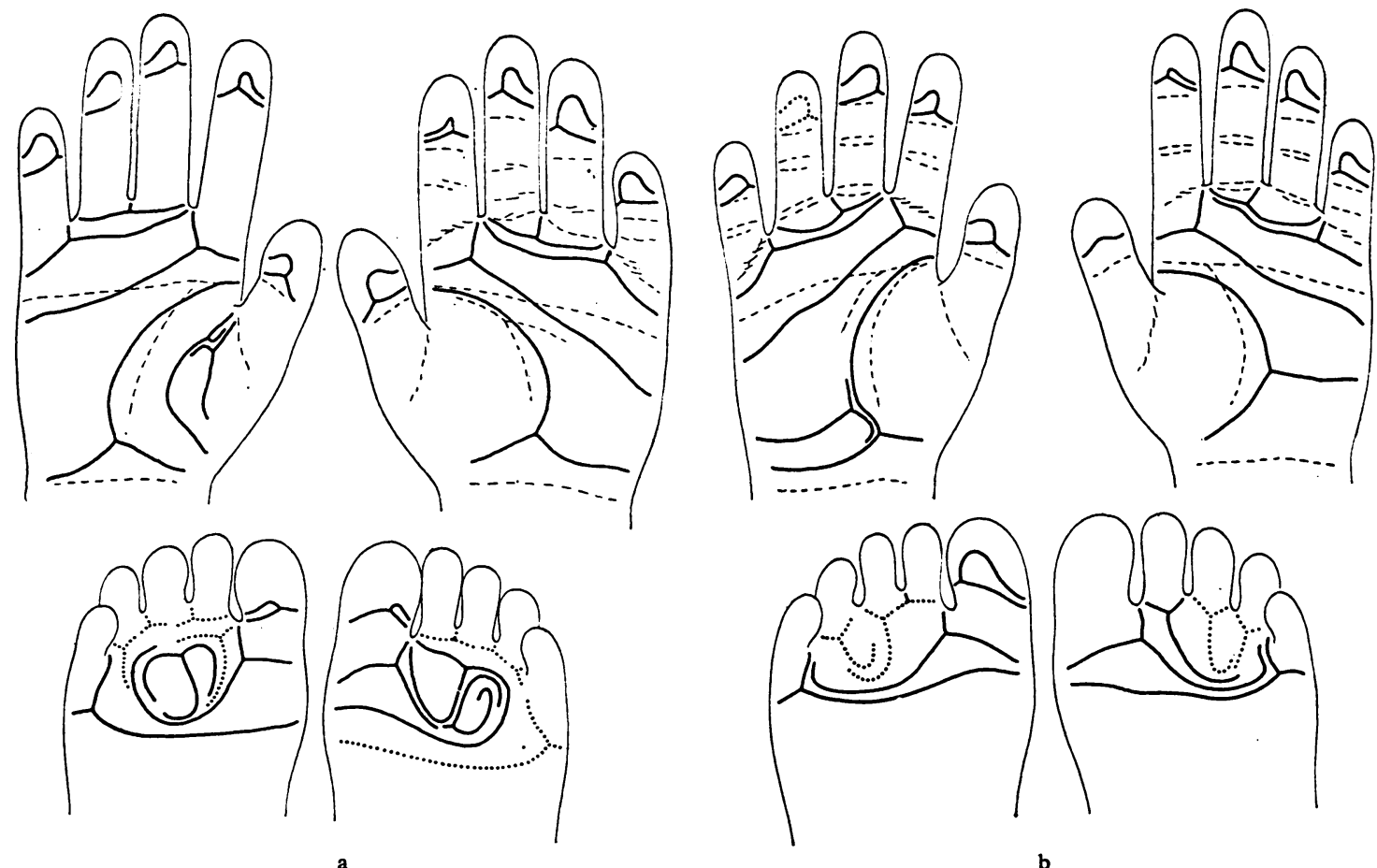

FIG. 4. Dermatoglyphs of (a) IV. 1 ; (b) IV.2.

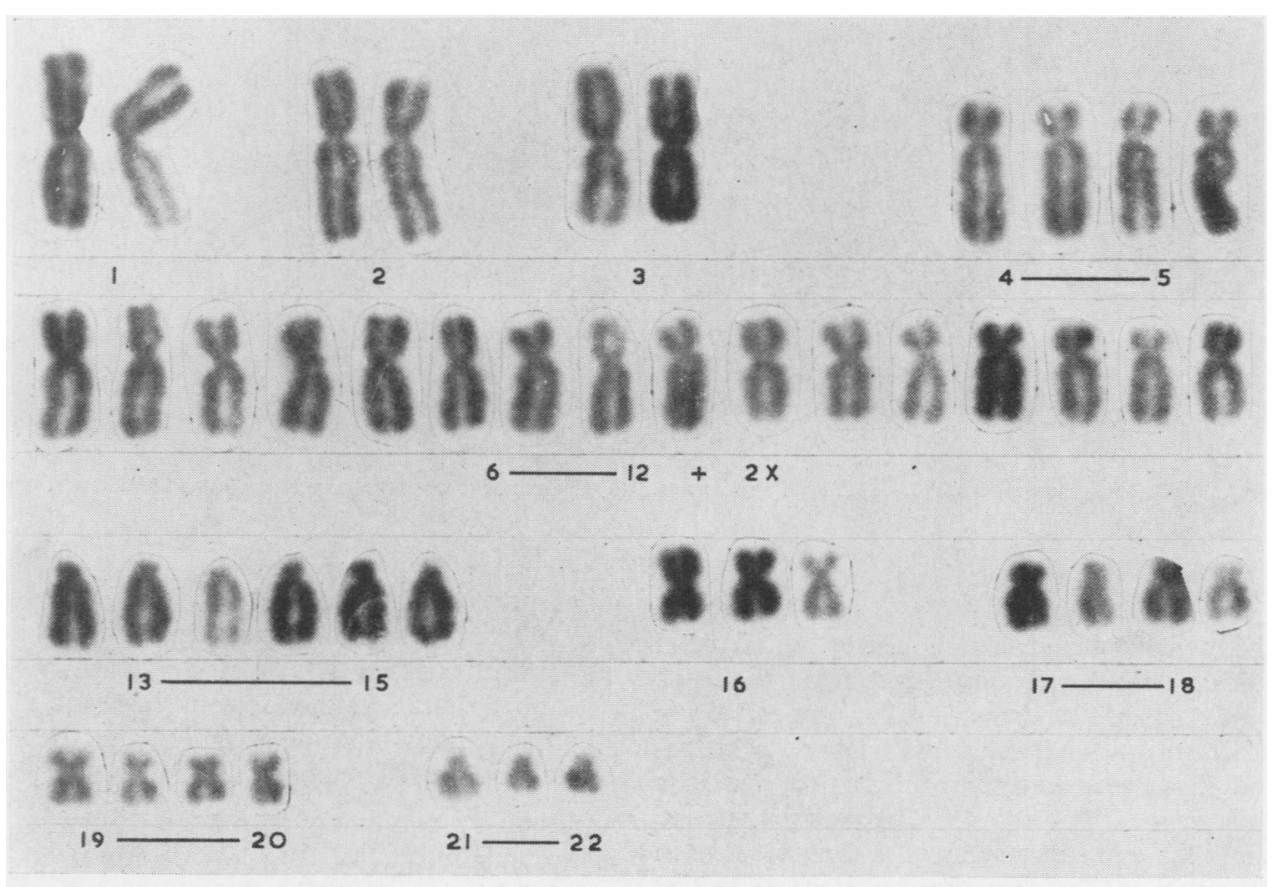

FIG. 5. Karyotypes of (a) IV.1; and, opposite (b) IV.2; and (c) mother (III.7). 


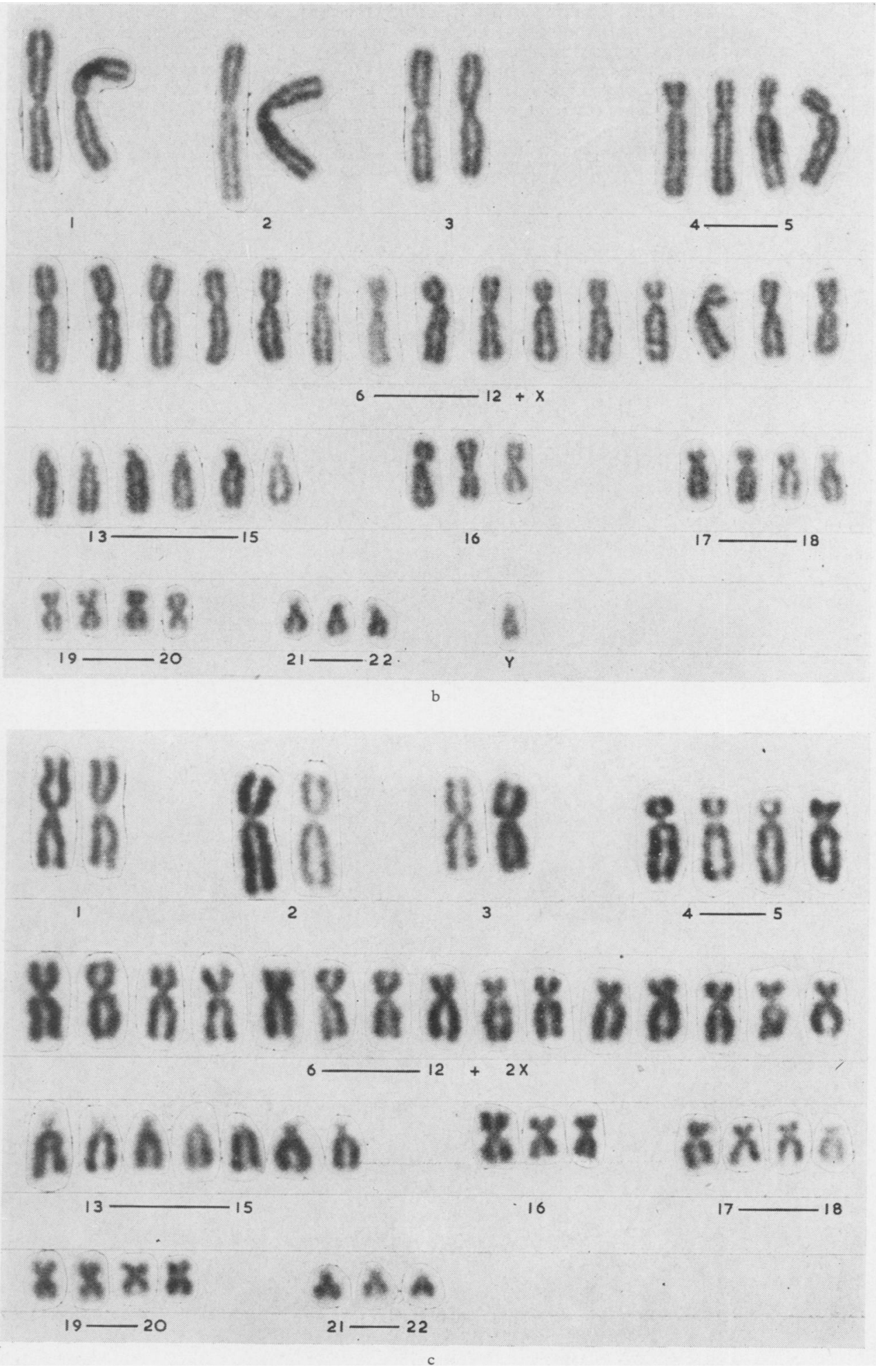


Royal Infirmary); Professor C. Dent for urine analysis; Dr. P. D. C. Kinmont for his clinical report; Professor L. Penrose for dermatoglyphic studies; Professor $\mathrm{H}$. Harris and Dr. E. Robson for biochemical linkage studies; Dr. I. Dunsford for blood grouping; and finally the family concerned who have shown great interest and co-operation over the past two years.

This work was carried out during the tenure of a Mental Health Research Fund Fellowship (P.M.L.) to study the chromosome complements of families showing two or more cases of non-specific mental subnormality.

\section{REFBRENCES}

Gray, J. E., Dartnall, J. A., Creery, R. D. G., and Croudace, J. (1966a). Congenital anomalies due to transmission of a chromosome translocation. f. med. Genet., 3, 59.

,-- and Macnamara, B. G. P. (1966b). A family showing transmission of a translocation between a 6-12 chromosome and a 21-22 chromosome. ibid., 3, 62 . 